\title{
Saw Palmetto-Based Nutritional Supplement Prostataplex Relieves Symptoms of Benign Prostatic Hyperplasia (BPH) in Patients with Mild to Moderate BPH
}

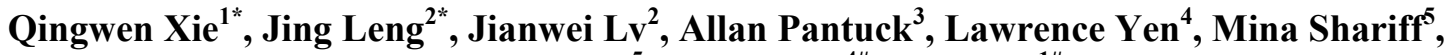 \\ Kenneth Kami ${ }^{5}$, Jianyu Rao ${ }^{4 \#}$, Rong Shi ${ }^{1 \#}$ \\ ${ }^{1}$ Department of Preventive Medicine, School of Public Health, Shanghai Jiao Tong University School of Medicine, Shanghai, China \\ ${ }^{2}$ Department of Urology, Shanghai Renji Hospital, Shanghai Jiao Tong University School of Medicine, Shanghai, China \\ ${ }^{3}$ Department of Urology, David Geffen School of Medicine, University of California, Los Angeles, USA \\ ${ }^{4}$ Department of Pathology and Laboratory Medicine, David Geffen School of Medicine, University of California, Los Angeles, USA \\ ${ }^{5}$ Department of Research, DRM Resources, Costa Mesa, USA \\ Email: " shirong61@yahoo.com.cn, ${ }^{*}$ jrao@mednet.ucla.edu
}

Received June 13, 2012; revised July 5, 2012; accepted July 12, 2012

\begin{abstract}
The goal of this study was to assess the efficacy of the saw palmetto-based nutritional supplement, Prostataplex, for relieving the symptoms associated with benign prostatic hyperplasia (BPH) in men with mild to moderate degrees of BPH. A randomized, double-blind, placebo-controlled trial was performed in Shanghai, China. Eighty patients with BPH were randomly assigned to either the intervention group (39 cases) or control group (41 cases). Patients in the intervention group were administered Prostataplex orally and placebos were given to patients in the control group. The duration of treatment was 12 weeks in both groups. Following the intervention of Prostataplex, the maximum urinary flow rates (MFR), total scores of International Prostate Symptom Score (IPSS) and quality of life indicators were significantly better among the patients in the intervention group than those in the control group $(P<0.01$ for all variables). Significant improvement of symptoms including dysuria, reducing nocturnal polyuria and increasing urinary flow rate was seen after two months of intervention, especially for the improvement of incomplete bladder emptying. Prostataplex has positive effects on improving symptoms as well as quality of life in men with mild to moderate $\mathrm{BPH}$.
\end{abstract}

Keywords: Saw Palmetto; Prostataplex; Benign Prostatic Hyperplasia; Intervention

\section{Introduction}

Benign prostatic hyperplasia (BPH) is a histological diagnosis characterized by proliferation of the cellular elements in a man's prostate, which though usually not a serious threat to health is associated with clinical symptoms that affect quality of life [1]. BPH affects men worldwide regardless of race. After age 40, the incidence of $\mathrm{BPH}$ rises by $10 \%$ every 10 years and reaches about $40 \%$ at the age of 50 [1]. BPH is a progressive disease. Early symptoms of the condition include urinary dribbling, slow urine stream and frequent nighttime urination (nocturia), and gradually progress to urinary hesitancy, urinary frequency, urgency, intermittency and incomplete bladder emptying, which seriously impact the patients' daily lives.

Prostataplex is a mixture of herb-derived supplements, with the main ingredient being saw palmetto. There have been multiple studies to examine the effects of saw pal-

\footnotetext{
*The two authors contributed equally to this work.
}

${ }^{\#}$ Corresponding authors. metto on BPH, and the long-term effect of saw palmetto for BPH is somewhat controversial [2-7]. However, a previous study from us showed that Prostataplex supplement exhibits short-term effects on improvement of clinical symptoms of $\mathrm{BPH}$, including relieving urinary frequency, urgency and dysuria [8]. The previous study was limited by the fact that the treated group had a higher IPSS score than the control group at the baseline. Furthermore, the study only measured the effect at the end of 3 months of intervention. To further examine the efficacy of this product on relieving symptoms of $\mathrm{BPH}$, the present study was carried out using a study design that was similar to the previous study, but only added the study of effects at different time intervals (1 month, 2 months and 3 months) after Prostataplex intervention.

\section{Materials and Methods}

\subsection{Materials}

Prostataplex, provided by Longlife, Inc. (Westminster, 
CA, USA), was essentially a similar saw-palmetto-based, dietary supplement used in the previous study with minor modifications. Other components include vitamin A, plant sterols, lycopene, pumpkin seed oil, palm oil and selenium. Placebos were also provided by Longlife, Inc., and were identical in appearance to the Prostataplex capsules, with the main composition being corn oil.

\subsection{Subjects}

Men aged over 40 years old who had benign clinical manifestations including dysuria, nocturia, urinary frequency, urinary urgency, urinary dribbling and slow urine stream, as well as prostate enlargement revealed by rectal examination, were involved in the current study. In addition, it was required that the maximum urinary flow rate (MFR) was less than $15 \mathrm{~mL}$, and the volume of urination was more than $100 \mathrm{~mL}$. The mean course of disease of the participants was 5.9 months. A total of 80 subjects were recruited into the study. These subjects were included after screening 100 subjects, including 17 who did not meet the study criteria (or meet the exclusion criteria) and 3 who refused to participate during the initial screen and recruiting period.

The exclusion criteria were: 1) Patients who had taken other drugs, herbs or non-prescription drugs within 4 weeks; 2) Patients who had prostate-specific antigen (PSA) level over $4 \mathrm{ng} / \mathrm{mL}$, serum creatinine (Cr) level over $16 \mu \mathrm{mol} / \mathrm{L}$, blood urea nitrogen (BUN) level over 8 $\mathrm{mg} / \mathrm{dL}$, urinary bacterial counts over $10,000 / \mathrm{mL}$ or a positive nitrite test; 3 ) Patients who had history of neurogenic bladder, bladder neck sclerosis, urethral stricture or prostate cancer; 4) Patients who had stones, recurrent urinary tract infections, renal insufficiency, cardiorespiratory insufficiency or abnormal liver function. Additional exclusion criteria were: patients who were unable to understand or follow the study protocol; patients who were involved in other clinical trials; patients whose BPH required surgical treatment as judged by an urologist; patients with previous bladder or prostate surgery; patients with known alcohol abuse; patients with known sensitivities to ingredients in the product; and patients who had significant depression or other psychiatric disease noted during the initial screening.

Subjects were recruited from the urology clinic at Renji Hospital of Shanghai Jiao Tong University. The study was approved by the Ethics Review Committee of the local health department. Informed consent was obtained from all participants following a detailed description of the purpose and potential benefits of the study.

\subsection{Subjects Entry and Randomization}

The 80 participants were randomly assigned to either the intervention group (39 cases) or control group (41 cases).
A randomized allocation method was used to assign the subjects into the intervention (Group 1) or placebo group (Group 2) in a blinded fashion.

\subsection{Study Duration and Patient Follow-Up}

The study procedure was the same as the previous study [8]. Briefly, the study had a 2 -week recruitment period, a 1-week washout period, and a 12-week follow-up period. After randomization, each subject received a container marked with a colored label with 30 pills inside. Patients in the intervention group were orally administered Prostataplex capsules 3 times a day (1 capsule each time). During each visit, a urologist also addressed specific concerns that the subjects might have, evaluated compliance and toxicity, and resupplied the patients with additional capsules. No serious or unexpected adverse events associated with the capsules were reported.

The following tests were conducted pre- and post-trial to assess the efficacy of Prostataplex for treatment of BPH. 1) International Prostate Symptom Score (IPSS). IPSS is an 8-question written screening tool used to rapidly diagnose and suggest management of the symptoms of BPH. Patients answer 7 symptom questions, each assigning a score from 1 to 5 for a total maximum of 35 points, and a detailed description can be found in our previous publication [8]. A higher score indicates the severity of the disease. 2) An eighth quality of life question asks, "If you were to spend the rest of your life with your urinary condition the way it is now, how would you feel about that?" with answer scores ranging from 0 (delighted) to 6 (terrible) [8]. 3) B-ultrasonography measured the prostate volume using the following formula: prostate volume $=0.52 \times$ transverse diameter $\times$ superoinferior diameter $\times$ anteroposterior diameter. 4) Urodynamics test determined MFR. 5) Laboratory examinations, like routine urine tests, determined the PSA, Cr and BUN levels.

In addition, urinary symptom and quality of life questionnaires were also collected at 1-month, 2-month and 3-month intervals post-intervention.

\subsection{Statistical Analysis}

All data were entered in EpiData and all statistical analyses were performed using the statistical software, Statistical Package for the Social Sciences v. 11.5 (SPSS 11.0, SPSS Inc., Chicago, IL, USA).

\section{Results}

A total of 80 subjects were recruited in the study, including 39 in the intervention and 41 in the placebo control group. The mean age of the subjects in intervention group was $63.53 \pm 8.37$ years old and the mean age of the con- 
trol group was $62.90 \pm 7.42$ years old. At the baseline, the 2 groups were compatible for course of disease (month), serum levels of PSA/BUN/Cr, maximum urinary flow rate, volume of urination, residual urine volume, prostate length/width/height/volume, IPSS score, quality of life indicator and rectal examination (Table 1).

At the end of 3 months of intervention, the MFR, IPSS total scores and quality of life indicators were improved among the patients in the intervention group than those in the control group (all $P$ values $<0.01$ ) (Table 2). Comparing preversus post-treatment indicators within each group (Table 3), MFR, volume of urination, IPSS total score and quality of life indicators showed significant differences in the intervention group $(P<0.01$ for all), but not in the control group. Notably, prostate length in the intervention group decreased significantly post-intervention compared to pre-intervention $(P<0.05)$. There was slightly increased urinary volume in the control group after versus before the study $(P=0.02)$. Inter- estingly, there was a statistically significant difference observed in rectal examinations in the control group preand post-intervention due to the feeling of an enlarged prostate gland or nodule present $(P=0.002)$.

Tables 4 and 5 show the effects of Prostataplex on improving BPH-related urological symptoms at different time points, including 4 weeks, 8 weeks and 12 weeks postintervention. Relative to the control group, improvement of voiding symptoms including incomplete bladder emptying, nocturia, and frequency of urination were seen in the intervention group at 2 months and more at 3 months after intervention $(P<0.01$ for both). In the intervention group, the percentages of patients with improvement of incomplete bladder emptying were $59 \%$ and $79.5 \%$, respectively, at 8 weeks and 12 weeks post-intervention.

\section{Discussion}

Consistent with our previous study [8], the present study

Table 1. Basic clinical characteristics of subjects in the intervention and control groups at baseline.

\begin{tabular}{|c|c|c|c|c|}
\hline Clinical characteristic & Intervention group $($ Mean \pm SD) & Control group (Mean \pm SD) & $t$ & $P$ \\
\hline Mean age (years) & $63.53 \pm 8.37$ & $62.90 \pm 7.42$ & 0.894 & 0.374 \\
\hline Course of disease (month) & $6.67 \pm 10.63$ & $5.17 \pm 1.36$ & 0.355 & 0.723 \\
\hline PSA $(\mu \mathrm{g} / \mathrm{L})$ & $1.85 \pm 0.99$ & $2.22 \pm 1.23$ & 1.461 & 0.148 \\
\hline BUN (mmol/L) & $4.52 \pm 1.85$ & $5.03 \pm 1.64$ & 1.313 & 0.193 \\
\hline $\mathrm{Cr}(\mathrm{mmol} / \mathrm{L})$ & $67.95 \pm 43.32$ & $76.23 \pm 28.23$ & 1.017 & 0.312 \\
\hline Maximum urinary flow rate $(\mathrm{mL} / \mathrm{s})$ & $10.69 \pm 2.57$ & $11.63 \pm 2.83$ & 1.556 & 0.124 \\
\hline Volume of urination $(\mathrm{mL})$ & $183.87 \pm 41.66$ & $189.671 \pm 40.41$ & 0.633 & 0.529 \\
\hline Residual urine volume (mL) & $14.56 \pm 15.76$ & $14.76 \pm 18.26$ & 0.050 & 0.960 \\
\hline Prostate length $(\mathrm{mm})$ & $43.49 \pm 5.17$ & $42.54 \pm 5.69$ & 0.781 & 0.437 \\
\hline Prostate width (mm) & $39.74 \pm 5.79$ & $40.15 \pm 4.84$ & 0.338 & 0.736 \\
\hline Prostate height (mm) & $37.64 \pm 5.29$ & $37.85 \pm 4.87$ & 0.187 & 0.852 \\
\hline Prostate volume $\left(\mathrm{cm}^{3}\right)$ & $34.39 \pm 10.96$ & $34.27 \pm 11.81$ & 0.045 & 0.964 \\
\hline IPSS total score & $16.51 \pm 4.90$ & $16.27 \pm 3.74$ & 0.252 & 0.802 \\
\hline Quality of life indicator & $4.08 \pm 0.81$ & $4.10 \pm 0.77$ & 0.117 & 0.907 \\
\hline Rectal examination & $1.95 \pm 1.234$ & $1.90 \pm 1.091$ & 0.178 & 0.859 \\
\hline
\end{tabular}

Table 2. Comparison of the clinical indicators of subjects in the intervention and control groups post-intervention.

\begin{tabular}{|c|c|c|c|c|}
\hline Clinical indicator & Intervention group (Mean \pm SD) & Control group (Mean \pm SD) & $t$ & $P$ \\
\hline PSA $(\mu \mathrm{g} / \mathrm{L})$ & $1.94 \pm 0.90$ & $1.94 \pm 0.89$ & 0.022 & 0.983 \\
\hline $\mathrm{BUN}(\mathrm{mmol} / \mathrm{L})$ & $4.31 \pm 1.71$ & $4.83 \pm 1.24$ & 1.547 & 0.126 \\
\hline $\mathrm{Cr}(\mathrm{mmol} / \mathrm{L})$ & $67.63 \pm 21.33$ & $70.22 \pm 20.81$ & 0.550 & 0.584 \\
\hline Maximum urinary flow rate $(\mathrm{mL} / \mathrm{s})$ & $18.04 \pm 4.47$ & $12.80 \pm 3.55$ & 5.822 & 0.001 \\
\hline Volume of urination $(\mathrm{mL})$ & $215.29 \pm 77.75$ & $205.01 \pm 56.03$ & 0.681 & 0.498 \\
\hline Residual urine volume (mL) & $11.74 \pm 14.86$ & $14.71 \pm 16.07$ & 0.855 & 0.395 \\
\hline Prostate length $(\mathrm{mm})$ & $42.72 \pm 5.17$ & $42.39 \pm 5.51$ & 0.275 & 0.784 \\
\hline Prostate width (mm) & $39.69 \pm 5.24$ & $40.46 \pm 5.11$ & 0.667 & 0.507 \\
\hline Prostate height (mm) & $37.87 \pm 4.69$ & $38.02 \pm 4.75$ & 0.145 & 0.885 \\
\hline Prostate volume $\left(\mathrm{cm}^{3}\right)$ & $33.94 \pm 10.21$ & $34.66 \pm 11.96$ & 0.287 & 0.775 \\
\hline IPSS total score & $9.82 \pm 5.30$ & $14.95 \pm 3.86$ & 4.967 & 0.001 \\
\hline Quality of life indicator & $2.54 \pm 1.00$ & $3.88 \pm 0.781$ & 6.673 & 0.001 \\
\hline Rectal examination & $1.95 \pm 1.19$ & $2.20 \pm 1.19$ & 0.926 & 0.357 \\
\hline
\end{tabular}


Table 3. Comparison of the clinical indicators of subjects in the intervention and control groups pre- and post-intervention.

\begin{tabular}{ccccc}
\hline Clinical indicator & \multicolumn{2}{c}{ Intervention group } & \multicolumn{2}{c}{ Control group } \\
\cline { 2 - 5 } PSA $(\mu \mathrm{g} / \mathrm{L})$ & $t$ & 0.503 & 1.646 & 0.108 \\
BUN $(\mathrm{mmol} / \mathrm{L})$ & 0.677 & 0.518 & 0.683 & 0.498 \\
Cr $(\mathrm{mmol} / \mathrm{L})$ & 0.652 & 0.967 & 1.315 & 0.196 \\
Maximum urinary flow rate $(\mathrm{mL} / \mathrm{s})$ & 0.042 & 0.001 & 1.996 & 0.053 \\
Volume of urination $(\mathrm{mL})$ & 9.183 & 0.002 & 2.346 & 0.02 \\
Residual urine volume $(\mathrm{mL})$ & 3.271 & 0.202 & 0.019 & 0.985 \\
Prostate length $(\mathrm{mm})$ & 1.297 & 0.012 & 0.473 & 0.639 \\
Prostate width $(\mathrm{mm})$ & 2.629 & 0.884 & 0.278 & 0.208 \\
Prostate height $(\mathrm{mm})$ & 0.147 & 0.416 & 0.593 & 0.556 \\
Prostate volume $\left.(\mathrm{cm})^{3}\right)$ & 0.822 & 0.001 & 1.646 & 0.108 \\
IPSS total score & 10.150 & 0.001 & 2.463 & 0.018 \\
Quality of life indicator & 9.647 & 0.009 & 0.000 & 0.000 \\
Rectal examination & 2.757 & 0.503 & 3.354 & $0.002^{*}$ \\
\hline
\end{tabular}

*Statistically significant difference was observed in the control group, due to the feeling of an enlarged prostate gland or nodule present.

Table 4. Comparison of the cases with improved symptoms in the intervention and control groups on 1, 2 and 3 months post-intervention.

\begin{tabular}{|c|c|c|c|c|c|c|}
\hline \multirow{2}{*}{ Time } & \multicolumn{2}{|c|}{ Intervention group } & \multicolumn{2}{|c|}{ Control group } & \multirow{2}{*}{$\chi^{2}$} & \multirow{2}{*}{$P$} \\
\hline & Improvement ${ }^{*}$ & No changes & Improvement ${ }^{*}$ & No changes & & \\
\hline 4 weeks & 9 & 30 & 7 & 34 & 0.450 & 0.500 \\
\hline 8 weeks & 22 & 17 & 11 & 30 & 7.217 & 0.007 \\
\hline 12 weeks & 35 & 4 & 15 & 25 & 24.098 & 0.000 \\
\hline
\end{tabular}

*The improvement indicates improvement of incomplete bladder emptying and reductions in frequency of urination and nocturnal polyuria.

Table 5. The improved symptoms of cases in the intervention and control groups on 1, 2 and 3 months post-intervention (n, \%).

\begin{tabular}{|c|c|c|c|c|c|c|c|c|c|c|}
\hline \multirow[b]{2}{*}{ Time } & \multicolumn{5}{|c|}{ Intervention group } & \multicolumn{5}{|c|}{ Control group } \\
\hline & $\begin{array}{l}\text { Improvement } \\
\text { of incomplete } \\
\text { bladder } \\
\text { emptying }\end{array}$ & $\begin{array}{l}\text { Reductions } \\
\text { in } \\
\text { nocturnal } \\
\text { polyuria }\end{array}$ & $\begin{array}{l}\text { Reductions } \\
\text { in frequency } \\
\text { of urination }\end{array}$ & $\begin{array}{l}\text { No. } \\
\text { change }\end{array}$ & Worsening & $\begin{array}{l}\text { Improvement } \\
\text { of incomplete } \\
\text { bladder } \\
\text { emptying }\end{array}$ & $\begin{array}{l}\text { Reductions } \\
\text { in nocturnal } \\
\text { polyuria }\end{array}$ & $\begin{array}{l}\text { Reductions } \\
\text { in frequency } \\
\text { of urination }\end{array}$ & $\begin{array}{l}\text { No. } \\
\text { change }\end{array}$ & Worsening \\
\hline 4 weeks & $\begin{array}{c}7 \\
(17.9 \%)\end{array}$ & $\begin{array}{c}1 \\
(2.6 \%)\end{array}$ & 0 & $\begin{array}{c}31 \\
(79.5 \%)\end{array}$ & 0 & $\begin{array}{c}1 \\
(2.4 \%)\end{array}$ & 0 & 0 & $\begin{array}{c}40 \\
(97.6 \%)\end{array}$ & 0 \\
\hline 8 weeks & $\begin{array}{c}23 \\
(59.0 \%)\end{array}$ & $\begin{array}{c}2 \\
(5.1 \%)\end{array}$ & $\begin{array}{c}1 \\
(2.6 \%)\end{array}$ & $\begin{array}{c}13 \\
(33.3 \%)\end{array}$ & 0 & $\begin{array}{c}7 \\
(17.1 \%)\end{array}$ & 0 & 0 & $\begin{array}{c}34 \\
(82.9 \%)\end{array}$ & 0 \\
\hline 12 weeks & $\begin{array}{c}31 \\
(79.5 \%)\end{array}$ & $\begin{array}{c}4 \\
(10.3 \%)\end{array}$ & $\begin{array}{c}1 \\
(2.6 \%)\end{array}$ & $\begin{array}{c}3 \\
(7.7 \%)\end{array}$ & 0 & $\begin{array}{c}14 \\
(34.1 \%)\end{array}$ & 0 & 0 & $\begin{array}{c}24 \\
(58.5 \%)\end{array}$ & $\begin{array}{c}3 \\
(7.3 \%)\end{array}$ \\
\hline
\end{tabular}

showed that the saw palmetto-based, dietary supplement, Prostataplex, had significant effects in relieving patients with symptoms associated with $\mathrm{BPH}$, and such effects can be seen after only 2 months of intervention. Although the current study had a similar design and sample size as the previous study, it was done in a different patient population, i.e., subjects with mild to moderate $\mathrm{BPH}$. Following intervention, IPSS score reduced, MFR increased and the prostate volume shrank in patients in the intervention group. In the control group, although there was somewhat increased urinary volume, other important
BPH-related measurements and clinical symptoms were unchanged. In fact, rectal examinations showed the feeling of prostate enlargement or the presence of nodules more prominently after the study in control group.

Prostataplex is a dietary supplement which consists of many components, yet the main, active component appears to be saw palmetto. The effect of saw palmetto on $\mathrm{BPH}$ is still controversial [2-8]. Most studies [2-6], including our previous study [8], seem to support that saw palmetto per se, or supplements containing saw palmetto as a main ingredient, has the effect to relieve symptoms 
of $\mathrm{BPH}$, at least for short terms. However, in a randomized trial conducted by Bent et al. [7], 225 men with moderate-to-severe symptoms of $\mathrm{BPH}$ received either saw palmetto extract (160 mg twice daily) or placebo. At the end of 1 year of treatment, no significant differences were noted between saw palmetto recipients and placebo recipients in IPSS scores and MFR. In addition, no differences were seen in secondary endpoints, such as quality of life scores, sexual function scores, residual urine volume and prostate volume. However, even in this negative study, some beneficial effects were observed in the short term ( 3 months), which was consistent with our findings.

One should keep in mind that there are other components in Prostataplex that may exert positive effects on relieving symptoms of $\mathrm{BPH}$. One such component is lycopene. Recent studies have shown that lycopene has strong antioxidant properties [9] and that lycopene significantly inhibits the progression of BPH [10]. Lycopene is a member of the carotenoid family of compounds, which is mainly found in tomatoes. As Prostataplex contains both saw palmetto and lycopene, it is entirely possible that both ingredients contributed to the positive effects in BPH patients.

The exact mechanisms of Prostataplex on improving the BPH-related symptoms remain unclear. The current study shows that the capsule reduces prostate size, shrinks enlarged prostates, and relieves or eliminates the obstruction caused by mechanical compression of the prostate on the urinary tract. However, such an effect was not seen in our previous study [8]. Whether such a difference of observation is due to different patient populations (the previous study included patients with more severe BPH while current patients have mild to moderate $\mathrm{BPH}$ ) remain to be determined. Also it is unclear whether the effect is due to saw palmetto alone or its combination with other components, etc. Nevertheless, our study demonstrated again that the saw palmetto-based Prostataplex supplement has positive effects to relieve BPHrelated symptoms in patients with mild to moderate $\mathrm{BPH}$ within 2 months after intervention.

\section{REFERENCES}

[1] D. G. Bostwick and J. N. Eble, "Urologic Surgical Pa- thology," Mosby, St. Louis, 1997.

[2] G. S. Gerber, "Saw Palmetto for the Treatment of Men with Lower Urinary Tract Symptoms," Journal of Urology, Vol. 163, No. 5, 2000, pp. 1408-1412. doi:10.1016/S0022-5347(05)67631-8

[3] G. S. Gerber, et al., "Saw palmetto (Serenoa repens) in Men with Lower Urinary Tract Symptoms: Effects on Urodynamic Parameters and Voiding Symptoms," Urology, Vol. 51, No. 6, 1998, pp. 1003-1007. doi:10.1016/S0090-4295(98)00143-5

[4] H. W. Bauer, et al., "Saw Palmetto Fruit Extract for Treatment of Benign Prostatic Hyperplasia. Results of a Placebo-Controlled Double-Blind Study," $M M W$ Fortschritte der Medizin, Vol. 141, No. 25, 1999, p. 62.

[5] J. Sokeland, "Combined sabal and Urtica Extract Compared with Finasteride in Men with Benign Prostatic Hyperplasia: Analysis of Prostate Volume and Therapeutic Outcome," British Journal of Urology International, Vol. 86, No. 4, 2000, pp. 439-442.

doi:10.1046/j.1464-410X.2000.00776.X

[6] J. M. McPartland and P. L. Pruitt, "Benign Prostatic Hyperplasia Treated with Saw Palmetto: A Literature Search and an Experimental Case Study," The Journal of the American Osteopathic Association, Vol. 100, No. 2, 2000, pp. 89-96.

[7] S. Bent, C. Kane, K. Shinohara, J. Neuhaus, E. S. Hudes, H. Goldberg and A. L. Avins, "Saw Palmetto for Benign Prostatic Hyperplasia," The New England Journal of Medicine, Vol. 354, No. 6, 2006, pp. 557-566. doi:10.1056/NEJMoa053085

[8] R. Shi, Q. Xie, X. Gang, J. Lun, L. Cheng, A. Pantuck and J. Rao, "Effect of Saw Palmetto Soft Gel Capsule on Lower Urinary Tract Symptoms Associated with Benign Prostatic Hyperplasia: A Randomized Trial in Shanghai, China," Journal of Urology, Vol. 179, No. 2, 2008, pp. 610-615. doi:10.1016/j.juro.2007.09.032

[9] H. Azimi, A. A. Khakshur, I. Aghdasi, M. Fallah-Tafti and M. A. Abdollahi, "Review of Animal and Human Studies for Management of Benign Prostatic Hyperplasia with Natural Products; Perspective of new Pharmacological Agents," Inflammation \& Allergy-Drug Targets, Vol. 11, No. 3, 2012, pp. 207-221. doi: $10.2174 / 187152812800392715$

[10] S. Schwarz, U. C. Obermüller-Jevic, E. Hellmis, W. Koch, G. Jacobi and H. K. Biesalski, "Lycopene Inhibits Disease Progression in Patients with Benign Prostate Hyperplasia," Journal of Nutrition, Vol. 138, No. 1, 2012, pp. 49-53. 